\title{
A AVALIACCÃO DA EDUCAÇÃO SUPERIOR PELO MUNDO DO TRABALHO
}

GUSTAVO HENRIQUE MORAES

TACIANA CORDAZZO

PAULO ROBERTO WOLLINGER

\section{RESUMO}

O Sistema Nacional de Avaliação da Educação Superior completou dez anos em 2014, consolidando uma política pública bem-sucedida que vinculou os processos regulatórios aos resultados da avaliação, induzindo a qualidade do ensino. Essa avaliação, contudo, ainda tem pouca articulação com o mundo do trabalho, ficando mais restrita ao campo acadêmico e não superando a lógica que dissocia a universidade da sociedade. O Ministério da Educação, no enfrentamento dessa situação, firmou uma politica colaborativa com os conselhos federais de regulamentação profissional, incluindo-os no processo regulatório. Os resultados dessa política que articula avaliação, ensino superior e trabalho ainda não foram explorados pela comunidade acadêmica, configurando uma lacuna na pesquisa educacional. Apresentam-se, com este artigo, a concepção, a análise e alguns resultados desse processo, valendo-se da investigação empirica do convênio celebrado junto ao Conselho Federal de Administração.

PALAVRAS-CHAVE AVALIAÇÃO DA EDUCAÇÃO • ENSINO SUPERIOR - SINAES • CONSELHOS FEDERAIS DE REGULAMENTAÇÃO PROFISSIONAL. 


\section{RESUMEN}

El Sistema Nacional de Avaliação da Educação Superior cumplió diez años en el 2014, consolidando una exitosa política pública que vinculó los procesos regulatorios a los resultados de la evaluación y mejoró la calidad de la enseñanza. Sin embargo, esa evaluación todavía está poco articulada al mundo del trabajo, se restringe más al campo académico y no supera la lógica que disocia la universidad de la sociedad. El Ministerio de Educación, para enfrentar tal situación, creó una política colaborativa con los consejos federales de reglamentación profesional, incluyéndolos en el proceso regulatorio. Los resultados de dicha política, que articula evaluación, educación superior y trabajo todavía no han sido explorados por la comunidad académica y configuran una laguna en la investigación educativa. En este artículo se presentan la concepción, el análisis y algunos resultados de ese proceso por medio de la investigación empírica del convenio celebrado junto al Consejo Federal de Administración.

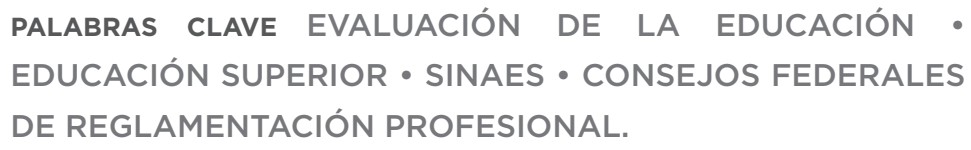

\section{ABSTRACT}

The Sistema Nacional de Avaliação da Educação Superior completed ten years in 2014, consolidating a successful public policy that aligned the regulatory processes to the results of evaluation, leading to the quality of education. This evaluation, however, still has little connection with the world of work, being more restricted to the academic field and not being able to overcome the logic that dissociates the University from the society. The Ministry of Education, in the face of this situation, signed a collaborative policy with federal professional regulatoryboards, involving them in the regulatory process. The results of this policy that align evaluation, higher education and work have not been explored by the academic community yet, configuring a gap in educational research. This article presents the design, analysis and some results of this process based on the empirical investigation of the agreement entered into with the Federal Council of Administration.

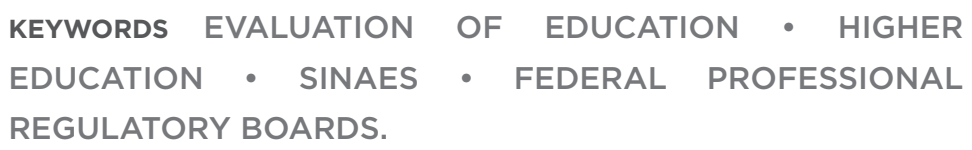




\section{INTRODUÇÃO}

Em 2014, o Sistema Nacional de Avaliação da Educação Superior (Sinaes) completou dez anos, fundamentando-se na "promoção do aprofundamento dos compromissos e responsabilidades sociais das instituições de educação superior" (BRASIL, 2004, Art. $1^{\circ}, \S 1^{\circ}$ ). Ao estabelecer que os resultados das avaliações configurassem o referencial básico para os processos de regulação e supervisão, o Sinaes induziu a qualidade do ensino como o fator principal de análise, por parte do Ministério da Educação (MEC), para as decisões relativas à autorização de funcionamento de cursos e de instituições de ensino superior (IES). Nas palavras do ex-ministro e

1 Fernando Haddad foi ministro da Educação no período de 2005 a 2012 Sua gestão marca a implantação e a consolidação do Sinaes. idealizador do Sinaes, Fernando Haddad (2006): " "O processo de avaliação precisa produzir resultados. Não basta apontarmos quais cursos e instituições são melhores ou piores. Isso precisa refletir-se na regulação". Passados dez anos, é amplamente aceita na academia a ideia de que o Sinaes permitiu a apresentação de um panorama mais completo da educação superior que está sendo ofertada no Brasil (POLIDORI; MARINHO-ARAÚJO; BARREYRO, 2006), constituindo-se como 
uma das políticas mais exitosas já desenvolvidas pelo MEC, embora seja preciso levar em consideração o perigo de sua descaracterização pelo "flagelo nacional da descontinuidade da política” (LIMANA, 2008, p. 872).

Uma disposição inovadora do Sinaes, pouco considerada nas análises sobre o sistema, encontra-se no Decreto n. 5.773/06 (BRASIL, 2006), que abriu aos conselhos federais de regulamentação profissional a possibilidade de participar do processo de regulação da educação superior. ${ }^{2}$ Algumas opiniões, tais como a do professor Gabriel Mário Rodrigues (2007), sugerem que essas novas disposições nascem de pressões das corporações profissionais que desejam formatar o curso de acordo com seus interesses classistas, obedecendo aos ditames do mercado (CAPPI, 2006) e ferindo a autonomia universitária. Outro foco de oposição localiza-se no setor privado e pode ser sintetizado no pensamento do fundador do Grupo Anhanguera, Antônio Carbonari Neto (2006): "os conselhos, por lei, precisam fiscalizar os profissionais, não os formandos. Os instrumentos que eles têm não são melhores que os do MEC".

Por meio da expressão de outro entendimento - o de que a formação superior deve aproximar-se da prática da futura atividade profissional, a fim de atender as reais necessidades produtivas do país (MORAES; WOLLINGER, 2012) -, a Secretaria de Educação Superior (SESu) do MEC iniciou a aplicação dessas possibilidades legais a partir de agosto de 2009, por intermédio da celebração de termos de colaboração entre o MEC e os conselhos federais de representação profissional. ${ }^{3}$ Na opinião da então secretária da SESu, Maria Paula Dallari Bucci (2009): " "Estamos superando uma cultura marcada por separação entre Estado e sociedade no que diz respeito a políticas públicas. Agora, a postura é de envolvimento."

Apesar da intensa movimentação, pouco - ou quase nada foi registrado a respeito dessa importante política, em curso há mais de cinco anos. $\mathrm{O}$ inesperado silêncio acadêmico deve-se, em certa medida, aos próprios conselhos federais, que, majoritariamente, mostraram-se não preparados para atender as especificidades da nova atribuição. Contudo, contrariando essa tendência, destacou-se o trabalho desenvolvido pelo
2 A inovação prevista no Art. 37 altera e amplia as disposições previstas pelo antigo decreto regulamentador - Decreto n. 3.860, de 9 de julho de 2001 -, que restringia essa prerrogativa ao Conselho Federal da Ordem dos Advogados do Brasil (OAB)

3 Entre agosto de 2009 e dezembro de 2010, 17 conselhos federais celebraram o termo de colaboração com o MEC, a saber: Conselho Federal de Administração (CFA), Conselho Federal de Biblioteconomia (CFB), Conselho Federal de Biologia (CFBio), Conselho Federal de Biomedicina (CFBM), Conselho Federal de Contabilidade (CFC), Conselho Federal de Educação Física (Confef), Conselho Federal de Enfermagem (Cofen), Conselho Federal de Engenharia, Arquitetura e Agronomia (Confea), Conselho Federal de Farmácia (CFF), Conselho Federal de Fisioterapia e Terapia Ocupacional (Cofito), Conselho Federal de Fonoaudiologia (CFF), Conselho Federal de Medicina (CFM), Conselho Federal de Medicina Veterinária (CFMV), Conselho Federal de Nutricionistas (CFN), Conselho Federal de Odontologia (CFO),

Conselho Federal de Psicologia (CFP) e Conselho Federal de Química (CFQ).

4 Maria Paula Dallari Bucci dirigiu a SESu no período 2008-2010 e foi a última titular da pasta a encaminhar atividades de regulação e supervisão. Após sua saída, a recém-criada Secretaria de Regulação e Supervisão da Educação Superior (Seres/MEC) incorporou essas atribuições, diminuindo o escopo de atuação da SESU. 
5 Alerta-se os leitores de que os autores deste artigo integraram as equipes técnicas que conceberam a metodologia proposta pelo MEC/CFA/CRA-PR, respondendo solidariamente por eventuais incoerências metodológicas apontadas por investigação posterior

6 Concorda-se aqui com os autores que defendem não haver distinção clara entre os métodos qualitativos e quantitativos, uma vez que toda pesquisa quantitativa é, também qualitativa (RICHARDSON, 2007)
Conselho Federal de Administração (CFA) em parceria com o Conselho Regional de Administração do Paraná (CRA-PR). Durante o ano de 2011, o CRA-PR realizou a avaliação profissional de 21 cursos de Administração no estado.

A existência de um processo real abriu caminho para uma investigação empírica a respeito dessa política pública, com base na qual se propõem aqui três questões investigativas: "Como, efetivamente, foi constituída a participação do CFA no Sinaes?”; “Quais foram os resultados do processo avaliativo em questão?" e "Quais são as contribuições dessa experiência histórica para o Sinaes?”. Procura-se com este estudo buscar respostas a tais questionamentos.

\section{INDICAÇÕES METODOLÓGICAS}

A natureza do estudo exigiu a concepção de duas etapas metodológicas. A primeira, desenvolvida no âmbito institucional do MEC, do CFA e do CRA-PR, diz respeito aos procedimentos e instrumentos utilizados para a constituição de um sistema avaliativo e caracteriza-se como descritiva, pois procura descrever os fatos e fenômenos de determinada realidade e as relações entre as variáveis (GIL, 2007). A segunda, desenvolvida pelos autores deste artigo, delimita a análise dos resultados produzidos pelas avaliações realizadas pelo CRA-PR e caracteriza-se pelo método dialético, segundo o qual os fatos não podem ser tomados fora de um contexto social, político e econômico (DIEHL; TATIM, 2004). Ambas as etapas configuram uma pesquisa aplicada, pois têm como motivação básica a solução de problemas concretos ou de aplicação prática.

Quanto aos procedimentos técnicos utilizados, destacam-se os seguintes: a observação-participante, uma vez que os pesquisadores participaram efetivamente do processo estudado; ${ }^{5}$ a pesquisa documental, utilizando como fontes os escritos dos 21 relatórios adaptados tratados mediante técnicas qualitativas, como a análise de conteúdo e o tratamento estatístico, modelado de forma a quantificar os fenômenos qualitativos ${ }^{6}$ típicos da área educacional. As descrições pormenorizadas dos procedimentos e instrumentos metodológicos de pesquisa são apresentadas 
nas seções seguintes, dispostas de modo a responder às perguntas propostas na introdução da pesquisa.

\section{A CONSTITUIÇÃO DA PARTICIPAÇÃO DO CFA NO SINAES (METODOLOGIA DE AVALIAÇÃO)}

A partir da assinatura do Termo entre o MEC e os conselhos federais, uma série de ações foi desencadeada. A primeira delas, protagonizada pelo MEC, reuniu representantes dos conselhos para capacitação junto ao sistema de fluxo eletrônico de processos (e-MEC). Aos fluxos processuais já estabelecidos, a SESu incorporou uma nova etapa na qual os conselhos passaram a ter acesso aos processos de autorização, reconhecimento e renovação de reconhecimento dos cursos ligados a suas representações. A manifestação dos conselhos foi prevista por meio da submissão de um relatório de manifestação técnica, elaborado por uma comissão de especialistas, conforme descrito na cláusula segunda do Termo:

b) $\bigcirc$ relatório de manifestação técnica terá formato eletrônico, definido pela SESU/MEC, e será parte integrante do processo regulatório de Autorização, Reconhecimento e de Renovação de Reconhecimento de cursos no âmbito do Sistema e-MEC;

c) O Conselho Federal de Administração definirá uma comissão de especialistas nas áreas de sua responsabilidade, composta por profissionais a ele vinculados, para elaborar as referidas manifestações técnicas bem como para estabelecer a interlocução com a SESU/MEC. (BRASIL, 2009)

Na capacitação, a SESu apresentou um modelo de relatório, privilegiando três dimensões avaliativas, assim definidas:

- Pertinência: buscava evidenciar a situação do curso quanto à oferta de vagas e à empregabilidade. Apontava dois indicadores: oferta regional do curso e inserção profissional do egresso. Sugeriu-se que os conselhos considerassem o total de profissionais em exercício na apreciação da necessidade da abertura de novos cursos. 
7 Foram bastante citadas as obras referentes à realização do Plano de Aceleração do Crescimento (PAC) Minha Casa, Minha Vida, Pré-Sal, Copa do Mundo e Olimpíadas no Brasil
- Relevância: buscava evidenciar os impactos das atividades da IES na região em que está inserida. Contava com três indicadores: reconhecimento e respeitabilidade da IES pela comunidade, perspectivas de inserção laboral e demandas sociais. É interessante observar que, nesta dimensão, a preocupação regulatória se deslocou do presente para o futuro, diagnosticando uma demanda profissional que estava por vir. ${ }^{7}$

- Inovação: dimensão com ênfase na estruturação do curso no que se refere às novidades na concepção do projeto pedagógico do curso. Seus indicadores foram: linha de formação e projeto pedagógico.

Cumpre registrar que os técnicos do MEC alertaram para o perigo - a ser evitado - da inversão de papéis, o que levaria o MEC a opinar sem propriedade sobre o setor produtivo e os conselhos, por sua vez, a fazerem análises inválidas sobre aspectos educacionais. O sucesso da parceria dependeria, inevitavelmente, do equilíbrio entre essas distintas competências.

Dando sequência à parceria, em junho de 2010 foi realizada a Convenção do Sistema CFA/CRAs, ${ }^{8}$ na qual foram encaminhadas duas importantes questões: a descentralização da avaliação do CFA para os conselhos regionais e a possibilidade, concedida pelo MEC, de que "cada Conselho tenha seu próprio formulário de avaliação, que poderá ser modificado e aperfeiçoado de acordo com características específicas" (MORAES, 2010, p. 27).

Em decorrência dessas diretrizes, o CRA-PR constituiu a Comissão para Assuntos de Educação (PARANÁ, 2011a), que ponderou sobre as necessárias adaptações ao relatório e sobre a metodologia que deve ser utilizada para a efetivação das avaliações. Os trabalhos apontaram para a idealização de dois instrumentos metodológicos: o fluxograma interno dos processos de avaliação e o relatório de parecer técnico adaptado.

A finalidade do fluxograma era auxiliar o entendimento global do processo, além de organizar as informações geradas por seus atores: avaliadores, delegados, comissão, supervisão e presidência. Resumindo o fluxo processual, tem-se: 
uma vez recebidos pelo CRA-PR, os processos eram encaminhados para um avaliador designado pelo órgão; esse avaliador, devidamente anunciado, seria o responsável pela visita in loco às IES e pela posterior elaboração do relatório adaptado; nessa etapa, integrava-se à equipe um delegado local do CRA-PR que auxiliava o avaliador em entendimentos particulares da região; por fim, a comissão reunia-se para a decisão processual e o imediato encaminhamento à presidência do CRA-PR. O fluxograma completo, transposto do original, é apresentado a seguir.

QUADRO 1 - Fluxograma interno dos processos de avaliação

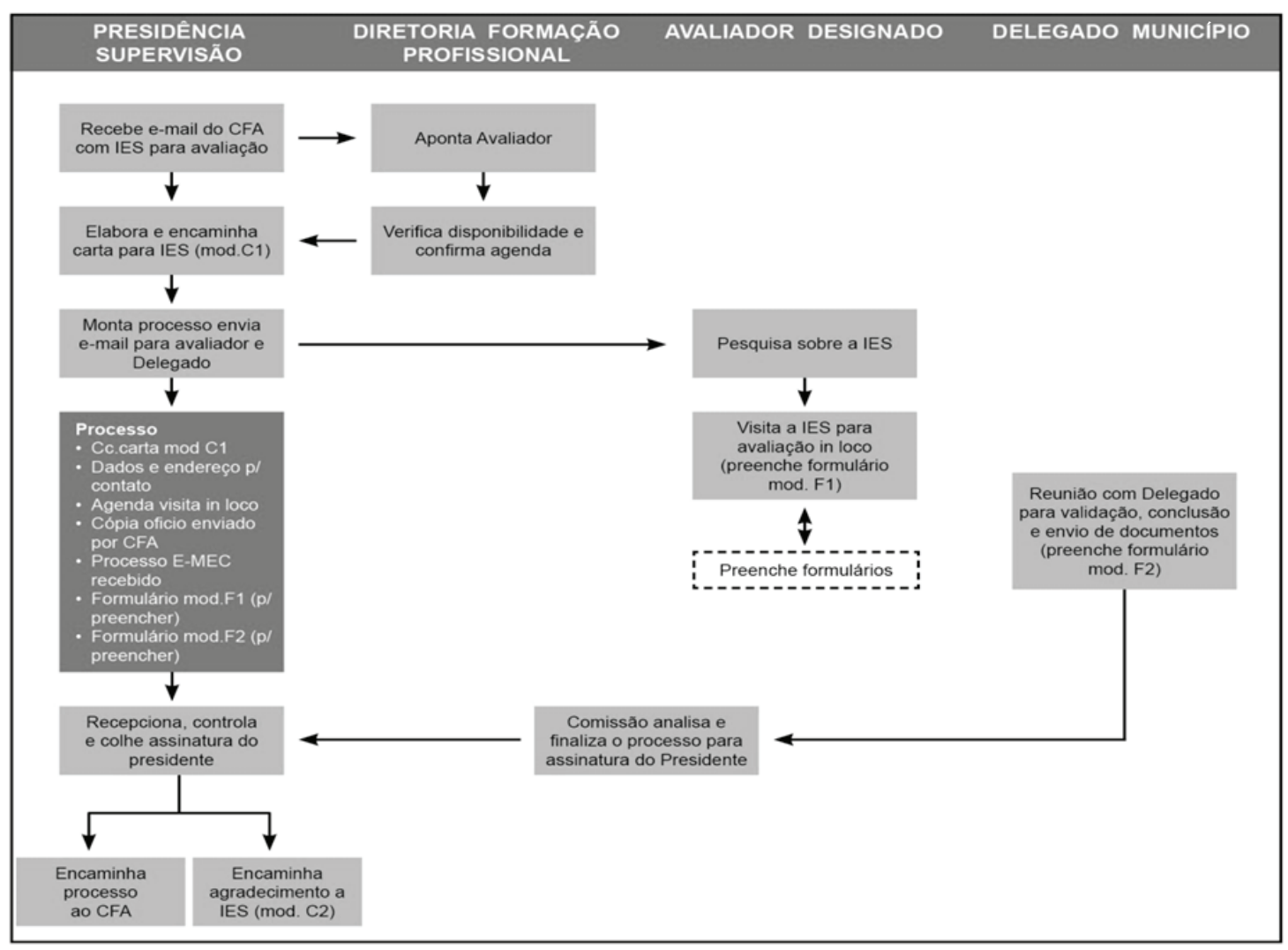

Fonte: Fluxo de processo das avaliações (CRA-PR, 2011).

O relatório adaptado incorporou elementos que o CRA-PR julgou imprescindível adicionar às dimensões, assim dispostos: 
- Pertinência: solicitou-se ao avaliador o levantamento dos cursos de Administração disponíveis na região, o número de vagas ofertadas e de vagas preenchidas.

- Relevância: definiram-se quais instituições seriam consultadas para a investigação da imagem da IES na comunidade. Internamente, verificou-se a existência de políticas de inserção e acompanhamento dos alunos e ex-alunos no mundo do trabalho e a incidência de projetos de iniciação científica, cultural e ambiental.

- Inovação: detalhou-se a existência de linha de formação e demais aspectos diferenciadores da IES e do projeto pedagógico do curso no cenário regional.

Para os conceitos avaliativos, o CRA-PR acatou a escala qualitativa proposta pelo MEC: satisfatório (S), parcialmente satisfatório (PS) e insatisfatório (I) para a avaliação das dimensões e favorável (F) e desfavorável (D) para o parecer final.

Uma análise dialética, contudo, deve considerar que os instrumentos de pesquisa nunca operam em um ambiente estéril, livre de influências externas. Assim, é importante registrar que nos 21 processos do Sinaes analisados, todos os avaliadores designados pelo CRA-PR eram professores de cursos de Administração, além de participarem, de alguma forma, da gestão do conselho. Tal arranjo configurou um estilo de pensamento (FLECK, 2010) que se refletirá nos resultados das avaliações investigadas, apresentados na seção seguinte.

\section{RESULTADOS DAS AVALIAÇÕES}

Compilando os resultados extraídos dos 21 pareceres técnicos, é possível apresentar o seguinte resumo qualitativo das avaliações, exposto no Quadro 2. 
QUADRO 2 - Resumo qualitativo das avaliações

\begin{tabular}{|c|c|c|c|c|c|c|c|c|c|}
\hline & \multirow[t]{2}{*}{ ATO } & \multicolumn{2}{|c|}{ PERTINÊNCIA } & \multicolumn{3}{|c|}{ RELEVÂNCIA } & \multicolumn{2}{|c|}{ INOVAÇĀO } & \multirow[t]{2}{*}{$\begin{array}{l}\text { PARECER } \\
\text { FINAL }\end{array}$} \\
\hline & & $\begin{array}{c}\text { Oferta } \\
\text { Regional } \\
\text { de curso }\end{array}$ & $\begin{array}{l}\text { Inserção } \\
\text { profissional } \\
\text { do egresso }\end{array}$ & $\begin{array}{l}\text { Reconhecimento } \\
\text { e Respeitabilidade } \\
\text { da IES pela } \\
\text { Comunidade }\end{array}$ & $\begin{array}{c}\text { Perspectiva } \\
\text { de inserção } \\
\text { laboral }\end{array}$ & $\begin{array}{l}\text { Demandas } \\
\text { sociais }\end{array}$ & $\begin{array}{l}\text { Linhas de } \\
\text { Formação }\end{array}$ & $\begin{array}{c}\text { Projeto } \\
\text { Pedagógico }\end{array}$ & \\
\hline 1 & Autorização & PS & PS & PS & $s$ & $\mathrm{~s}$ & $\mathrm{~s}$ & $s$ & $\mathrm{~F}$ \\
\hline 2 & Autorização & PS & PS & $\mathrm{s}$ & $\mathrm{s}$ & $\mathrm{s}$ & $\mathrm{s}$ & $\mathrm{s}$ & $\mathrm{F}$ \\
\hline 3 & Autorização & PS & S & s & PS & S & $S$ & PS & $\mathrm{F}$ \\
\hline 4 & Autorização- EAD & PS & s & PS & s & S & $S$ & PS & $\mathrm{F}$ \\
\hline 5 & Reconhecimento-EAD & PS & $s$ & $s$ & $\mathrm{~s}$ & $\mathrm{~s}$ & s & $s$ & $\mathrm{~F}$ \\
\hline 6 & Renovação & PS & PS & $S$ & S & S & S & PS & $\mathrm{F}$ \\
\hline 7 & Renovação & PS & PS & $S$ & $S$ & S & PS & PS & $\mathrm{F}$ \\
\hline 8 & Renovação & PS & PS & S & $S$ & S & $S$ & PS & $\mathrm{F}$ \\
\hline 9 & Renovação & PS & PS & PS & PS & S & $S$ & PS & $\mathrm{F}$ \\
\hline 10 & Renovação & PS & s & s & s & s & $S$ & PS & $\mathrm{F}$ \\
\hline 11 & Renovação & 1 & PS & PS & PS & PS & $S$ & PS & $\mathrm{F}$ \\
\hline 12 & Renovação & PS & PS & S & PS & S & $S$ & s & $\mathrm{F}$ \\
\hline 13 & Renovação & PS & s & s & s & s & $S$ & s & $\mathrm{F}$ \\
\hline 14 & Renovação & PS & s & s & s & S & $S$ & s & $\mathrm{F}$ \\
\hline 15 & Renovação & PS & PS & s & s & S & PS & PS & $\mathrm{F}$ \\
\hline 16 & Renovação & PS & PS & PS & PS & S & $S$ & PS & $\mathrm{F}$ \\
\hline 17 & Renovação & PS & PS & $\mathrm{s}$ & $s$ & $\mathrm{~s}$ & $\mathrm{~s}$ & PS & $\mathrm{F}$ \\
\hline 18 & Renovação & PS & PS & $S$ & $\mathrm{~s}$ & $\mathrm{~s}$ & PS & PS & $\mathrm{F}$ \\
\hline 19 & Renovação & 1 & 1 & 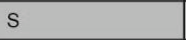 & $\mathrm{s}$ & $\mathrm{s}$ & PS & $s$ & $\mathrm{~F}$ \\
\hline 20 & Renovação & 1 & PS & PS & PS & PS & PS & PS & $\mathrm{F}$ \\
\hline 21 & Renovação & PS & PS & s & S & s & PS & PS & $\mathrm{F}$ \\
\hline
\end{tabular}

Fonte: Elaboração dos autores.

Observando a distribuição dos tipos de atos avaliados, percebe-se a prevalência das renovações de reconhecimento. Assim, o CRA-PR deparou-se majoritariamente com cursos já ofertados, frustrando as expectativas de um instrumento mais voltado às autorizações de novos cursos, principalmente em sua dimensão pertinência.

Outro aspecto que chama a atenção é que os relatórios não apontaram um conceito para cada dimensão. Essa lacuna metodológica força a adoção de uma análise centrada nos resultados dos indicadores, para a qual será considerada a distribuição de frequência apresentada na Tabela 1, que denota uma forte coerência avaliativa, com conceitos hegemônicos destacados em negrito. 
TABELA 1 - Distribuição de frequência de atribuição dos conceitos para indicadores e dimensões

\begin{tabular}{|c|c|c|c|c|c|c|c|c|}
\hline \multirow{3}{*}{$\begin{array}{c}\text { INDICADOR / DIMENSÃO } \\
\text { Oferta regional do curso (1) }\end{array}$} & \multicolumn{6}{|c|}{ CONCEITO } & \multirow{2}{*}{\multicolumn{2}{|c|}{ TOTAL }} \\
\hline & \multicolumn{2}{|c|}{ SATISFATÓRIO } & \multicolumn{2}{|c|}{$\begin{array}{l}\text { PARCIALMENTE } \\
\text { SATISFATÓRIO }\end{array}$} & \multicolumn{2}{|c|}{ INSATISFATÓRIO } & & \\
\hline & 0 & O\% & 18 & $86 \%$ & 3 & $14 \%$ & 21 & $100 \%$ \\
\hline Inserção profissional do egresso (2) & 6 & $29 \%$ & 14 & $67 \%$ & 1 & $5 \%$ & 21 & $100 \%$ \\
\hline Pertinência ( 1 e 2$)$ & 6 & $14 \%$ & 32 & $76 \%$ & 4 & $10 \%$ & 42 & $100 \%$ \\
\hline $\begin{array}{l}\text { Reconhecimento e respeitabilidade } \\
\text { da IES pela comunidade (3) }\end{array}$ & 15 & $71 \%$ & 6 & $29 \%$ & 0 & O\% & 21 & $100 \%$ \\
\hline Perspectiva de inserção laboral (4) & 15 & $71 \%$ & 6 & $29 \%$ & 0 & ०\% & 21 & $100 \%$ \\
\hline Demandas sociais (5) & 19 & $90 \%$ & 2 & $10 \%$ & 0 & O\% & 21 & $100 \%$ \\
\hline Relevância (3, 4 e 5) & 49 & $78 \%$ & 14 & $22 \%$ & 0 & O\% & 63 & $100 \%$ \\
\hline Linhas de formação & 15 & $71 \%$ & 6 & $29 \%$ & 0 & ०\% & 21 & $100 \%$ \\
\hline Projeto pedagógico & 7 & $33 \%$ & 14 & $67 \%$ & 0 & ०\% & 21 & $100 \%$ \\
\hline Inovação ( 6 e 7) & 22 & $52 \%$ & 20 & $48 \%$ & 0 & O\% & 42 & $100 \%$ \\
\hline
\end{tabular}

Fonte: Elaboração dos autores.

- Oferta regional do curso: avaliando o atual quadro de oferta de vagas para os cursos de Administração no estado do Paraná, a compreensão majoritária convergiu para o pouco conclusivo parecer parcialmente satisfatório. A utilização da análise documental, por sua vez, foi inequívoca ao apontar que as vagas já oferecidas pelas IES suplantavam, em muito, a demanda por cursos de Administração. Como exemplifica o extrato a seguir: "Com a facilidade de abertura de Faculdades na região, temos uma oferta considerável do curso de Administração na região sudoeste do Paraná" (PARANÁ, 2011b).

A alta incidência do tímido conceito PS parece apontar uma contradição: se no campo teórico prevalece o entendimento (do conselheiro) de que a expansão da profissão é urgente para o atendimento das necessidades nacionais, no campo prático a visão (do professor) demonstra a inutilidade da expansão da oferta, que já apresenta um alto índice de ociosidade de vagas: "o número médio de ingressantes é muito inferior ao total de vagas autorizadas” (PARANÁ, 2011c). 
"A Instituição tem condições necessárias para preencher um maior número de vagas ofertadas nos vestibulares, mas seu preenchimento está em torno de 50\% das vagas" (PARANÁ, 2011d).

- Inserção profissional do egresso: para esse indicador, esperava-se que o CRA-PR levantasse o número de administradores em exercício nas regiões dos cursos avaliados, no entanto nem todos os administradores em exercício estão filiados ao conselho, não constando em suas bases de dados. Ao contrário do que acontece com a área de Direito, por exemplo, em que o exercício profissional está necessariamente vinculado à $\mathrm{OAB}$, para a Administração não há consenso sobre funções profissionais privativas da categoria.

Essa impossibilidade técnica promoveu, a exemplo do indicador anterior, uma alta incidência do conceito PS, insuficiente para responder objetivamente à questão da empregabilidade, em especial na possibilidade do primeiro emprego. Na prática, os avaliadores voltaram suas atenções para um critério mais acadêmico do problema - as políticas institucionais de acompanhamento de egressos -, concluindo que as IES não atentavam para a vida profissional de seus alunos, estando distantes dessa missão institucional:

[...] em relação ao indicador inserção profissional do egresso, a IES não apresenta documentos formalizados e também não tem uma prática formalizada para monitorar e acompanhar a evolução dos egressos. (PARANÁ, 2011e, grifo nosso)

[...] porém, pela falta de um programa de acompanhamento do egresso, não há dados que mostram o exercício destes profissionais. (PARANÁ, 2011f, grifo nosso)

De forma conclusiva, os indicadores da pertinência denotaram que não faltam vagas em cursos de Administração das IES particulares no estado do Paraná e que os cursos existentes estão distantes da atividade profissional. Ainda assim, o CFA não se opõe à abertura de novos cursos, pois parte da compreensão de que em cada empresa brasileira 
9 Esta é a opinião expressa publicamente pelo presidente do CFA adm. Sebastião Mello.

10 Os recentes descredenciamentos da Universidade Gama Filho e da UniverCidade, no Rio de Janeiro, são suficientes para demonstrar como questões administrativas afetam diretamente as questões educacionais deve haver ao menos um bacharel em Administração trabalhando, ${ }^{9}$ realidade bastante distante da experimentada hoje.

- Reconhecimento e respeitabilidade da IES pela comunidade: a existência desse indicador revela uma crescente preocupação do Sinaes com a relação entre a IES e sua comunidade, não apenas em seu caráter educativo e cultural, mas também econômico. ${ }^{10}$ Vale registrar que neste estudo de caso todas as IES avaliadas são privadas e que - de maneira geral são bem vistas pela comunidade:

A IES é reconhecida pela comunidade, de acordo com as organizações contatadas, como uma Instituição de grande contribuição à inclusão social, ao desenvolvimento científico e tecnológico, à defesa do meio ambiente, da memória cultural. (PARANÁ, 2011g)

- Perspectiva de inserção laboral: estabelecendo um paralelo entre o outro indicador que trata da empregabilidade, nota-se uma possível contradição nas avaliações: ao passo que o indicador inserção profissional do egresso apresentou-se como parcialmente satisfatório, o indicador perspectiva de inserção laboral foi julgado, hegemonicamente, como satisfatório. A possível contradição é minimizada quando se considera que o primeiro indicador estava relacionado à realidade econômica atual, ao passo que o segundo vinculava-se às perspectivas futuras para a área, expressas em vários registros dos avaliadores:

[...] outro fator que pode auxiliar muito o crescimento da demanda da região é o fato de existirem rumores da instalação de uma montadora de automóveis na região. (PARANÁ, 2011h)

Existem perspectivas de crescimento na demanda por se tratar de região de fronteira, turística e industrializada, daí a importância do curso nessa dimensão. (PARANÁ, 2011c)

- Demandas sociais: julgado hegemonicamente como satisfatório (90\%), o último indicador ligado à relevância sintetizou o entender dos avaliadores quanto a essa dimensão. Convergiu para a ideia de que a expansão da área era 
necessária ao país, embora o curso de Administração seja o maior do Brasil, com mais de 830 mil matrículas em 2012 (BRASIL, 2013). Assim, se para a pertinência prevaleceu uma análise cautelosa, mais próxima à realidade da atividade docente, na relevância a avaliação apresentou tendência expansionista, mais próxima à política defendida pelo CFA.

É forçoso reconhecer aqui uma clara pressão corporativista, que defende a expansão da oferta como estratégia de fortalecimento do CFA. Esse posicionamento, porém, não é comum a todos os conselhos - a OAB e o CFM, por exemplo, defendem a restrição da oferta como estratégia de fortalecimento da profissão.

- Linhas de formação: a análise dos extratos relacionados a esse indicador convergiu para o entendimento de que o curso de Administração não deve contemplar linhas de formação - antes disso, deve consolidar-se em uma formação comum a esse bacharelado. De fato, o desacordo em relação às designações aplicadas ao curso de Administração, sendo a mais conhecida delas a de Administração de Empresas, é algo marcante entre os profissionais da área, que relatam constantemente o esforço necessário para solidificar a nomenclatura simples: bacharelado em Administração, garantida - após anos de reivindicação - pela Resolução CNE/CES n. 1, de 2 de fevereiro de 2004 (BRASIL, 2004). Assim, a ampla maioria dos avaliadores (71\%) atribuiu conceito satisfatório a esse indicador.

- Projeto pedagógico: em concordância com o entendimento apresentado para o indicador anterior, as análises relacionadas aos projetos pedagógicos privilegiaram, em vez da inovação, o respeito às diretrizes curriculares e a adequação à realidade local:

[...] a linha de formação do curso apresenta alto grau de sintonia com a realidade local. O Projeto Pedagógico do curso apresenta um modelo pedagógico consolidado, pautado em teorias e práticas, com diversificadas atividades que fazem com que o aluno construa o aprendizado constante e um perfil construtivista autônomo, acompanhado 
Apesar de não explicitarem a necessidade da inovação, as avaliações reconheceram - no mínimo - a escassez de posturas inovadoras. De fato, dois terços dos avaliadores atribuíram conceito parcialmente satisfatório ao indicador.

A percepção de que não houve nenhum conceito insatisfatório para os indicadores da dimensão inovação causa certa estranheza: será possível afirmar que as 21 IES avaliadas desempenham suas atividades de maneira inovadora, sem espaços para o ensino tradicional de Administração? Afirmar que todas as propostas são inovadoras não implica, logicamente, dizer que todas se equivalem e, portanto, que não há inovação? Alerta-se para a possibilidade de uma compreensão enviesada da dimensão que mereceria maior atenção.

\section{ANÁLISE DO PARECER}

Para todos os cursos avaliados, independentemente da tipologia do ato regulatório, o parecer final apontado pela comissão foi favorável. Uma ótica ingênua pode considerar que todas as IES possuíam requisitos acadêmicos satisfatórios e que as regiões onde estão inseridas proporcionavam um cenário propício à atuação profissional dos futuros administradores. Esse entendimento, contudo, pode ser refutado por uma análise mais crítica. Se tomado o exemplo da pertinência, para a qual não houve a atribuição de nenhum conceito satisfatório, é possível perguntar de que forma o resultado das dimensões poderia - efetivamente - influenciar a decisão final. A atribuição do julgamento favorável a processos de cursos claramente insatisfatórios (vide exemplo a seguir) reforça o questionamento da legitimidade dos uníssonos pareceres finais:

A faculdade deve formalizar e sistematizar seus projetos, ampliando sua importância na sociedade e nas empresas da região. Outro fator que se deve observar é a necessidade de se manter atualizada em seu currículo para acompanhar as mudanças sociais, culturais e econômicas em sintonia com a região de abrangência. (PARANÁ, 2011j) 
Com efeito, a uniformidade dos pareceres denota a fragilidade de uma metodologia que não estabeleceu como deveriam ser combinados os resultados das dimensões para que o avaliador pudesse se posicionar de forma coerente com os conceitos atribuídos. Nesse sentido, é possível, por meio de um esforço teórico-metodológico, propor uma lógica analítica baseada nos seguintes pressupostos:

- A cada dimensão deverá ser proposto um conceito final - satisfatório ou insatisfatório.

- Se a relevância for insatisfatória, o parecer final será desfavorável, em consonância com o disposto no Plano Nacional de Educação, que orienta a expansão da oferta atrelada às necessidades do país.

- A conjunção satisfatória da relevância e da pertinência deve resultar em um parecer favorável.

- Merece análise detalhada o processo julgado insatisfatório por sua pertinência, mas satisfatório por sua inovação, uma vez que projetos inovadores podem revitalizar uma área já saturada.

Com base nos pressupostos propostos e com o auxílio da lógica formal, pode-se organizar um quadro de referência para os pareceres finais (Quadro 3).

QUADRO 3 - Referência para os pareceres finais

\begin{tabular}{|c:c:c:c|}
\hline PERTINÊNCIA & RELEVÂNCIA & INOVAÇÃO & SUGESTÃO DE PARECER \\
\hline Insatisfatório & Insatisfatório & Insatisfatório & Desfavorável \\
\hline Insatisfatório & Insatisfatório & Satisfatório & Desfavorável \\
\hline Insatisfatório & Satisfatório & Insatisfatório & Desfavorável \\
\hline Insatisfatório & Satisfatório & Satisfatório & Analisar caso \\
\hline Satisfatório & Insatisfatório & Insatisfatório & Desfavorável \\
\hline Satisfatório & Insatisfatório & Satisfatório & Desfavorável \\
\hline Satisfatório & Satisfatório & Insatisfatório & Favorável \\
\hline Satisfatório & Satisfatório & Satisfatório & Favorável \\
\hline
\end{tabular}

Fonte: Elaboração dos autores. 
11 Conceito Enade, Conceito Preliminar de Curso (CPC), Conceito de Curso (CC), Índice Geral de Cursos (IGC) Conceito Institucional (Cl) e Índice de Diferença entre Desempenho Obtido e Esperado (IDD)

12 É um incômodo comum aos professores deparar-se com o popular questionamento: "Você trabalha ou só dá aulas"?

\section{CONTRIBUIÇÕES DESSA EXPERIÊNCIA AO SINAES (CONSIDERAÇÕES FINAIS)}

Ao completar dez anos, o sucesso do Sinaes demonstra que é possível estabelecer uma política regulatória pautada no resultado de avaliações educacionais. Os descredenciamentos de grandes universidades, a suspensão da oferta em centenas de cursos de graduação, a universalização do Exame Nacional de Desempenho de Estudantes (Enade) e o estabelecimento dos indicadores de qualidade da educação superior ${ }^{11}$ são provas suficientes de que o Sinaes está consolidado. Há, contudo, um aspecto no qual a educação superior brasileira não consegue avançar: o de sua necessária vinculação com a comunidade que a cerca, preocupando-se com a futura vida profissional de seus alunos. Ao contrário, prolifera-se um discurso que condena a aproximação das faculdades com o mundo profissional, sob o risco da instrumentalização da universidade pelo "mercado de trabalho".

Esse falso silogismo, que conecta diretamente a "profissão" ao "mercado", ignora a capacidade crítica dos professores universitários, além de negar a especificidade do trabalho humano contemporâneo, essencialmente profissional. É preciso não perder a compreensão de que toda graduação enseja uma atividade profissional, no setor público ou privado, na esfera produtiva ou na esfera cultural-simbólica, atuando como profissional liberal ou como assalariado, tais como os professores universitários. ${ }^{12}$

Nesse sentido, a parceria proposta pelo MEC vem procurando enfrentar a visão maniqueísta que opõe educação e trabalho. Ao contrário, as dimensões buscam a síntese necessária entre a oferta acadêmica e as necessidades nacionais. Não obstante, a análise dos resultados dessa experiência pioneira demonstrou algumas importantes fragilidades avaliativas:

- $\quad$ Falta de compreensão do papel dos conselhos no Sinaes: a inclusão da manifestação técnica dos conselhos no Sinaes objetivou a percepção de mais um olhar, diferente do acadêmico, na regulação da educação superior. O que se percebeu, na prática, foi a reprodução da lógica avaliativa do sistema. Ainda que o CRA-PR tenha modificado o instrumento avaliativo, não chegou a romper com a lógica tipicamente acadêmica dos instrumentos do MEC. 
Contribuiu para a manutenção do tradicional enfoque avaliativo o fato de que todos os avaliadores nomeados pelo CRA-PR eram professores universitários, mantendo o mesmo olhar epistemológico sobre o processo.

- Inadequação dos instrumentos de avaliação: outra fragilidade encontrada diz respeito ao não estabelecimento de critérios que balizassem os resultados da avaliação. Cabe relembrar que o relatório não previa a atribuição de um conceito final para cada dimensão, fato que dificultou a ponderação sugerida. É certo que essa simples alteração - a inclusão de conceito avaliativo para cada dimensão - representaria um avanço metodológico de análise. Seria possível, ainda, propor uma regra de julgamento mais aprofundada, que levasse em consideração os conceitos atribuídos a cada indicador. Como consequência imediata da falta de critérios avaliativos, os relatórios técnicos apresentaram inconsistências lógicas, tais como os pareceres finais favoráveis atribuídos a cursos claramente insatisfatórios.

- Ausência de informações estatísticas: esperava-se que o CFA enriquecesse a análise com elementos referentes à quantidade de profissionais em exercício na região, seguidos de seus índices de empregabilidade, desemprego e atuação junto à área de formação. Constatou-se, contudo, que os conselhos possuem dificuldade de informar quantos profissionais atuam em sua área, seja pela desatualização de suas bases de dados ou pelo desconhecimento dos processos estatísticos necessários para a realização desses levantamentos. Assim, os indicadores quantitativos foram praticamente desprezados nas avaliações.

- Necessidade de capacitação continuada: a estratégia de promover uma capacitação inicial para, posteriormente, atribuir certa autonomia aos conselhos não funcionou. Ao contrário da $\mathrm{OAB}$, que há anos empreende um sistema avaliativo, ${ }^{13}$ os conselhos não possuem a experiência necessária para empreender as avaliações propostas, necessitando de apoio mais direto das estruturas que compõem o Sinaes. Aqui, deve-se destacar o protagonismo
13 A participação da OAB na regulação da educação superior já estava prevista no Decreto n. 3.860, de 9 de julho de 2001. Some-se a isso o fato de esse órgão realizar seu Exame da Ordem de maneira unificada desde 2006 
do sistema CFA/CRAs, em especial do CRA-PR, que mesmo com essas dificuldades, estabeleceu uma metodologia e uma prática de avaliação.

Finalmente, é preciso compreender que as dificuldades relatadas acima não devem refutar a importância da experiência relatada. Antes disso, deve-se conservar o entendimento de que as inconsistências processuais são inerentes a qualquer processo inovador e que a realização prática dessa ideia regulatória constitui-se como uma etapa necessária - ainda que incompleta - para a tão esperada aproximação entre a universidade e o mundo do trabalho.

\section{REFERÊNCIAS}

BRASIL. Decreto n. 3.860, de 9 de julho de 2001. Dispõe sobre a organização do ensino superior, a avaliação de cursos e instituições, e dá outras providências. Brasília, DF: MEC, 2001. Disponível em: <http://www.google. com.br/url?sa=t\&rct=j\&q=\&esrc=s\&source=web\&cd=1\&ved=0CB0QFjAA\&ur l=http\%3A\%2F\%2Fportal.mec.gov.br\%2Fsesu\%2Farquivos\%2Fpdf\% 2FDecN3860.pdf\&ei=E0E5VbT8CpPhsAS22YHADw\&usg=AFQjCNFXRkUm BI4oSMY6VmbSc7X6tiyvlw>. Acesso em: 17 jan. 2015.

. Lei n. 10.861, de 14 de abril de 2004. Institui o Sistema Nacional de Avaliação da Educação Superior - Sinaes e dá outras providências. Brasília, DF: MEC, 2004.

. Decreto n. 5.773, de 6 de maio de 2006. Dispõe sobre o exercício das funções de regulação, supervisão e avaliação de instituições de educação superior e cursos superiores de graduação e seqüenciais no sistema federal de ensino. Brasília, DF: MEC, 2006.

BRASIL. Conselho Nacional de Educação. Resolução CNE/CES 01, de 2 de fevereiro de 2004. Estabelece as diretrizes curriculares do bacharelado em Administração. Brasília, DF: CNE, 2004.

BRASIL. Instituto Nacional de Estudos e Pesquisas Educacionais Anísio Teixeira. Censo da Educação Superior 2012. Brasília, DF: Inep, 2013.

BRASIL. Ministério da Educação; Conselho Federal de Administração. Termo de colaboração. Brasília, DF: MEC-CFA, 2009. Disponível em: <http://goo.gl/ CPNn4I > . Acesso em: 30 ago. 2012.

BUCCI, Maria Paula D. Autorização e reconhecimento terão participação de conselhos. Brasília, DF: MEC, 2009. Disponível em: <http://goo.gl/nKn3m5>. Acesso em: 29 ago. 2012.

CAPPI, Antonio. Decreto-Ponte: análise e sugestões. Brasília: Abruc, 2006. Disponível em: <http://goo.gl/uYP09V>. Acesso em: 29 ago. 2012. 
CARBONARI, Antônio. Conselhos de classe opinarão sobre cursos, por Fábio Takahashi. Folha de S. Paulo, 11 maio 2006. Disponível em: <http://goo.gl/ NTtgI9>. Acesso em: 9 out. 2014.

DIEHL, Astor Antônio; TATIM, Denise C. Pesquisa em ciências sociais aplicadas: métodos e técnicas. São Paulo: Prentice Hall, 2004.

FLECK, Ludwik. A gênese e o desenvolvimento de um fato científico. Belo Horizonte: Fabrefactum, 2010.

GIL, Antônio Carlos. Métodos e técnicas de pesquisa social. 5. ed. São Paulo: Atlas, 2007.

HADDAD, Fernando. MEC apresenta proposta para interligar avaliação e regulação do ensino superior. Brasília: MEC, 2006. Disponível em: <http://goo.gl/

HpYqGH>. Acesso em: 29 ago. 2012.

LIMANA, Amir. Desfazendo mitos: o que estão fazendo com o Sinaes? Revista Avaliação, Campinas, v. 13, n. 3, p. 869-873, 2008. Disponível em: <http://goo. gl/8BYLuq>. Acesso em: 17 jun. 2014.

MORAES, Gustavo Henrique. O processo de avaliação dos cursos de bacharelado em Administração: autorização, reconhecimento e renovação de reconhecimento. In: CONSELHO FEDERAL DE ADMINISTRAÇÃO.

Convenção do Sistema CFA/CRAs, 2010, Brasília. Anais... Brasília, DF, 2010.

MORAES, Gustavo Henrique; WOLLINGER, Paulo Roberto. A fragmentação das carreiras como estratégia de expansão da educação superior. Revista de Educação Pública, Cuiabá, v. 21, n. 47, p. 549-568, set./dez. 2012.

PARANÁ. Conselho Regional de Administração. Portaria n. 0092011 Nomeação da Comissão para Assuntos de Educação. Curitiba: CRA, 2011a. . Parecer do processo n. 201011536, de 26/04/2011. Curitiba: CRA, 2011b. . Parecer do processo n. 201107168, de 22/08/2011. Curitiba: CRA, 2011c. . Parecer do processo n. 201102827, de 18/08/2011. Curitiba: CRA, 2011d. . Parecer do processo n. 201004668, de 06/06/2011. Curitiba: CRA, 2011e. . Parecer do processo n. 201110868, de 28/09/2011. Curitiba: CRA, 2011f. . Parecer do processo n. 201012026, de 19/04/2011. Curitiba: CRA, 2011g. . Parecer do processo n. 20110210, de 28/07/2011. Curitiba: CRA, 2011h. . Parecer do processo n. 201101010, de 26/04/2011. Curitiba: CRA, $2011 \mathrm{i}$. . Parecer do processo n. 201100261, de 26/04/2011. Curitiba: CRA, 2011j.

POLIDORI, Marlis M.; MARINHO-ARAÚJO, Claisy; BARREYRO, Gladys Beatriz. Sinaes: perspectivas e desafios na avaliação da educação superior brasileira. Ensaio. Avaliação e Políticas Públicas em Educação, Rio de Janeiro, v. 14, n. 53, p. 425-436, out./dez. 2006.

RICHARDSON, R. Pesquisa social: métodos e técnicas. 3. ed. São Paulo: Atlas, 2007. 
RODRIGUES, Gabriel Mario. Reforma não avança, mas decreto introduz novidades positivas: entrevista. @prender. 0 portal do ensino superior. 2007. Disponível em: <http://goo.gl/7syJ0Y>. Acesso em: 9 out. 2014.

\section{GUSTAVO HENRIQUE MORAES}

Pesquisador em Informações e Avaliações Educacionais do Instituto Nacional de Estudos e Pesquisas Educacionais Anísio Teixeira (Inep), Brasília, Distrito Federal, Brasil profgustavomoraes@gmail.com

\section{TACIANA CORDAZZO}

Professora da Universidade Estadual de Ponta Grossa (UEPG), Ponta Grossa, Paraná, Brasil

tacianauepg@hotmail.com

\section{PAULO ROBERTO WOLLINGER}

Professor e Diretor de Ensino do Instituto Federal de Educação, Ciência e Tecnologia de Santa Catarina (IFSC), Florianópolis, Santa Catarina, Brasil

paulowollinger@gmail.com 
